\title{
Evolución de la cicatrización de la marca a fuego en equinos
}

\author{
Páez Barrios, J.R.'; Benítez, A.B. ${ }^{2}$ \\ ${ }^{1}$ Comisario Mayor M.V., División Rural, Policía del Chaco, Argentina. ${ }^{1,2}$ Cátedras Patología Quirúrgica y \\ Medicina Legal y Deontología, Facultad de Ciencias Veterinarias, UNNE, Sargento Cabral 2139, Corrientes \\ (3400), Argentina, Tel/Fax: (379) 4425753, E-mail: alibevet@hotmail.com.
}

\begin{abstract}
Resumen
Páez Barrios, J.R.; Benítez, A.B.: Evolución de la cicatrización de la marca a fuego en equinos. Rev. vet. 23: 2, 130-133, 2012. El propósito de este trabajo fue observar la evolución diaria del proceso de cicatrización de la marca a fuego en equinos y describir los cambios macroscópicos registrados hasta su completa resolución. La experiencia fue llevada a cabo en el predio de la División Rural de la Policía de la Provincia del Chaco (Resistencia, Argentina). Se emplearon 2 equinos de sexo hembra, pelajes bayo ruano y alazán tostado, cuyas edades fueron de 9 meses y 2 años y medio respectivamente. Ambos fueron marcados a fuego en lateral de la región femoral izquierda y mantenidos a campo en condiciones naturales, dándose por finalizado el estudio cuando la cicatrización fue completa en ambos animales, oscilando entre los 94 y 105 días. La documentación de los cambios producidos durante el proceso de cicatrización de la marca a fuego, asume importancia en medicina legal veterinaria, ya que servirá como patrón orientativo al momento de determinar el tiempo de estampada una marca a fuego, en hechos delictivos de abigeato, especialmente en adulteraciones de marcas, y permitirá fundamentar los trabajos periciales realizados por veterinarios.
\end{abstract}

Palabras clave: equino, marca a fuego, evolución de la cicatrización.

\begin{abstract}
Páez Barrios, J.R.; Benítez, A.B.: Hot branding healing evolution in horses. Rev. vet. 23: 2, 130-133, 2012. The experience was held on the campus of The Rural Police Division of Resistencia, Argentina, in two horses. Both animals were hot branded on the left side of the femoral region and kept under natural conditions (food and water ad libitum), considering the end of the study when the healing process was complete in both animals, lasting between 94 and 105 days, respectively. Documentation of changes during the healing process of hot branding is important from the veterinary forensic medicine point of view, since it will serve as an orientation guide in determining the time elapsed for a hot branding on crimes such as cattle rustling, especially in adulteration of brands, and will aid to fundament veterinarian forensic reports.
\end{abstract}

Key words: horse, scarring, branding, scar evolution.

\section{INTRODUCCIÓN}

La marca a fuego es una de las formas más antiguas de identificación de ganado mayor, existiendo constancia de su uso para acreditar la propiedad de animales bovinos y equinos en Argentina, desde el año $1585^{2}$. Consiste en un dibujo, diseño o signo, impreso o estampado sobre la piel con un hierro candente, que deja una marca o cicatriz indeleble, permanente en el tiempo ${ }^{8}$.

El propietario de hacienda debe registrar el diseño de su marca y señal en el organismo competente que cada provincia determine, el cual entrega al ganadero

Recibido: 21 junio 2012 / Aceptado: 20 julio 2012 un documento denominado "boleto de marcas y señales" que le confiere el derecho de uso exclusivo de la misma, por el plazo que las respectivas legislaciones locales establezcan ${ }^{8}$

Por su parte, existen leyes provinciales que establecen en general la obligatoriedad de la marcación, la edad mínima y máxima de los animales en la que debe realizarse, las zonas de estampado, las dimensiones del hierro, la utilización de contramarca en transacciones comerciales y la sustitución de la marca en los ejemplares de pura raza, por tatuajes y/o calimbos estampados a fuego $^{8}$

La instrumentación del sistema de marcas a fuego en Argentina, además de permitir testimoniar la propie- 
dad de los animales, constituye una de las medidas para controlar el abigeato, es decir, el delito rural consistente en el robo de ganado mayor o menor producido dentro de establecimientos rurales o durante el transporte de los mismos ${ }^{2}$. A pesar de ello, los hechos delictivos de esta naturaleza siguen afectando continuamente a los productores ganaderos y las autoridades judiciales solicitan la intervención de los médicos veterinarios para identificar a los animales implicados y elaborar informes periciales que permitan resolver problemas jurídicos relacionados a la marca que poseen, la antigüedad de la misma, si fue adulterada o no y el tipo de adulteración que sufrió ${ }^{3,4}$.

El objetivo de este trabajo fue describir los cambios macroscópicos producidos desde el primer día de estampada una marca a fuego en el equino hasta su completa cicatrización, los cuales servirán como fuente de datos al momento de determinar la antigüedad de una marca en casos de abigeato y permitirán orientar, clarificar y fundamentar los informes periciales realizados por los médicos veterinarios.

\section{MATERIAL Y MÉTODOS}

El trabajo fue llevado a cabo en el predio de la División Rural de la Policía de la Provincia del Chaco (Resistencia, Argentina). Se emplearon dos equinos de sexo hembra, de pelajes bayo ruano y alazán tostado y edades de 9 meses y 2 años y medio respectivamente. Ambos animales fueron marcados a fuego en la zona lateral de la región femoral izquierda. El hierro de marca elegido fue compatible con el diseño $\mathrm{CM}$, que presentaba una zona abierta representada por la $\mathrm{C}$ y una cerrada, la M, con ángulos en donde la transmisión de calor fue mayor y la quemadura fue más intensa. Los equinos fueron mantenidos a campo en condiciones naturales y trasladados diariamente al corral para realizar el seguimiento del proceso de cicatrización de la marca.

Tal seguimiento consistió en la observación y descripción de los cambios macroscópicos producidos durante el mencionado proceso, considerándose como primer día de observación aquél en que fue estampada la marca. Los cambios observados se documentaron mediante fotografías seriadas.

Cabe destacar que fue necesario realizar la depilación de la zona periférica de la marca, con tijera curva de cirugía, a partir del momento en que comenzó el crecimiento de pelos y a fin de facilitar la observación. El estudio se dio por finalizado cuando el proceso de cicatrización de la marca fue completo en ambos animales.

\section{RESULTADOS}

Se detallan los cambios macroscópicos observados durante el proceso de cicatrización de la marca a fuego en ambos equinos.

Día 1: inmediatamente de estampada la marca, se observó con nitidez el diseño de la misma, diferenciándose dos zonas, una central de color amarillento y as- pecto apergaminado, donde contactó el hierro candente y provocó la quemadura de tercer grado y una zona periférica representada por pelos chamuscados (Figura 1).

Día 2: ya no se observaron los pelos chamuscados en la zona periférica y la zona central se presentó igual que el día anterior.

Días 3 a 11: no hubo cambios en el proceso de cicatrización con respecto al día 2.

Día 12: la zona central presentó una imagen ondulada y se observó el desprendimiento de una pequeña zona, que provocó una hemorragia leve.

Días 16 y 17: el diseño de la marca perdió su nitidez. Fue claramente manifiesto el desprendimiento de pequeñas áreas de la quemadura de tercer grado, observándose por debajo un tejido congestivo de color rojo intenso. Esta etapa de desprendimiento es conocida como "pelechado de la marca" en el ambiente rural.

Días 18 a 23: continuó el desprendimiento de la quemadura de tercer grado igual que en los días 16 y 17. No se produjo aún crecimiento de pelo en la zona periférica de la marca.

Días 24 y 25: continuó el "pelechado" pero se observó una disminución de la congestión de la quemadura, la cual comenzó a cubrirse de escamas blancas.

Día 26: el "pelechado" fue completo (desprendimiento de toda la quemadura de tercer grado), quedando la marca de un color rosado pálido cubierta de escamas blancas y pequeños puntos sangrantes.

Día 30: se observó una imagen engrosada de la marca, que perdió nitidez al cubrirse de escamas blancas y pequeñas zonas con escaras rojas, en coincidencia con lugares donde hubo mayor transmisión de calor, es decir lugares cerrados del diseño, donde la quemadura fue más intensa (Figura 2).

Días 31 a 47: continuó el proceso de cicatrización sin cambios con respecto al día 30 , con excepción del día 37, en el cual comenzó el crecimiento de pelo en la zona periférica de la marca.

Día 48: se observó una retracción cicatrizal notable de la marca, cuyos bordes se hallaron cubiertos de escamas blancas.

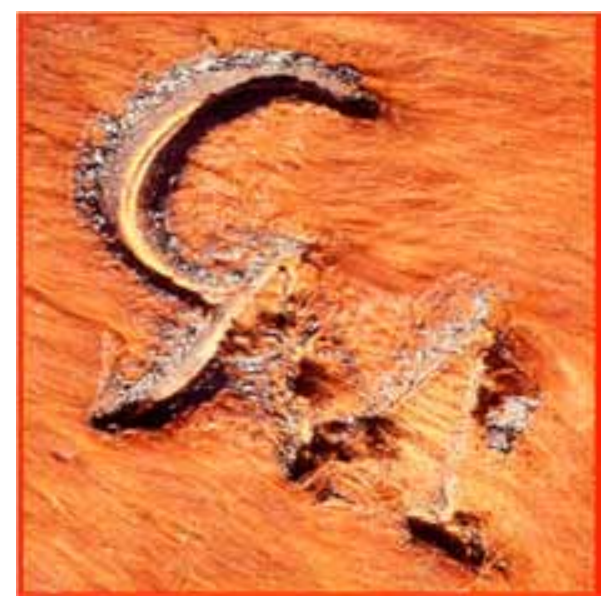

Figura 1. Marca a fuego con zona central de color amarillento y aspecto apergaminado; zona periférica con pelos chamuscados (día 1). 
Día 62: continuó el proceso de cicatrización observándose pequeños puntos congestivos en las zonas donde la quemadura fue más intensa.

Días 76 a 91: se encontró un solo punto congestivo, de color rosado sin cicatrizar en la punta inferior de la M.

El proceso de cicatrización no concluyó el mismo día en ambos equinos, ya que el alazán tostado manifestó cicatrización total el día 94, y en el bayo ruano, la misma recién se completó el día 105 (Figura 3).

\section{DISCUSIÓN}

El estampado del hierro candente provoca una quemadura de tercer grado o lesión cutánea de espesor completo, ya que destruye todas las capas de la piel y sus anexos. Los vasos subcutáneos superficiales sufren trombosis, mientras que los más profundos, excesivamente permeables, provocan edema del tejido subcutáneo. El área lesionada se presenta indolora debido a que los nervios también son destruidos ${ }^{1,5,6}$.

A los fines de manejo, en las quemaduras se consideran tres zonas concéntricas de lesión tisular: una zona interna o central, que contacta directamente con la fuente de calor, donde se produce necrosis por coagulación; una zona intermedia, de transición o de estasis capilar, con intensa reacción inflamatoria y daño tisular potencialmente reversible, y por último una zona más externa o periférica, que se presenta hiperémica, con mínimo compromiso celular y de recuperación espontánea y completa ${ }^{1,5,12}$.

En el presente trabajo estas zonas de lesión tisular pudieron evidenciarse ya que en la quemadura producida por la marca a fuego se pudo observar una zona central cubierta por una escara amarillenta o marrón oscura, seca, apergaminada, insensible al dolor $5,11,12$ que fue el residuo de los elementos cutáneos que coagularon por el calor o tejido carbonizado ${ }^{5,12}$. También se apreció una zona periférica con pelos chamuscados pero sin cambios de coloración, que manifestó un cre-

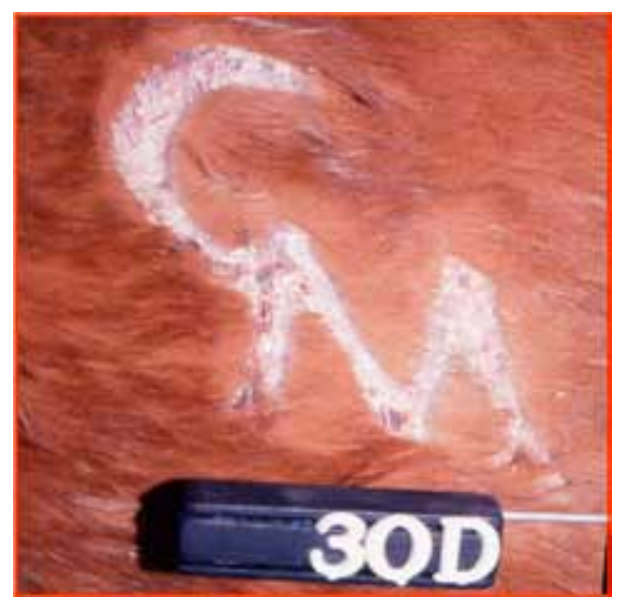

Figura 2. Marca a fuego con escamas blancas y zonas congestivas en sitios donde la quemadura fue más intensa (día 30). cimiento de pelos nuevos hacia el día 37. Con respecto a la zona de transición, en este caso no se pudo diferenciar claramente de la zona central, lo que concuerda con algunos autores que la describen como un área de injuria intermedia que al final de las $24 \mathrm{~h}$ suele volverse indistinguible de la zona coagulativa central ${ }^{1,5}$.

El proceso de cicatrización de una herida cutánea de espesor completo demanda un tiempo de 2 a 3 meses aproximadamente ${ }^{1}$, en el cual la epidermis se regenera desde los bordes mientras que la dermis, glándulas y folículos pilosos experimentan reparación tisular y son sustituidos por un tejido cicatrizal afuncional ${ }^{9}$, que consiste en una combinación de nuevos capilares, fibroblastos y tejido conectivo fibroso denominado tejido de granulación. Dicho tejido rellena la herida y se localiza por debajo de la escara ${ }^{1,5,6,7,9,10,11}$; en su etapa temprana tiene un lecho capilar muy rico y un color rojo fuerte, pero a medida que la cicatrización progresa adopta una coloración rosado pálida debido a que los nuevos vasos sanguíneos se desintegran por apoptosis ${ }^{9}$. Estos cambios son coincidentes con los registrados en los equinos bajo ensayo, destacándose aquí que la evolución de la coloración del tejido de granulación fue más lenta en ciertos lugares de la marca coincidentes con los ángulos cerrados del diseño del hierro y en una zona específica como fue la punta de la $\mathrm{M}$ del diseño, que recibieron mayor transmisión de calor y la quemadura fue más intensa.

Una vez formado el tejido de granulación, las células epidérmicas se movilizan por debajo de la escara y la separan de la superficie de la herida 7,9,10,11. Este hecho fue claramente manifiesto en nuestra experiencia, describiéndose como la caída de la quemadura de tercer grado o "pelechado de la marca" en el ambiente rural.

El tiempo que demanda la cicatrización total de una quemadura de tercer grado es de 2 a 3 meses aproximadamente. En esta experiencia, la cicatriz resultante de la quemadura por el hierro candente fue de aspecto liso, de forma coincidente con el diseño del hierro, sin pelos,

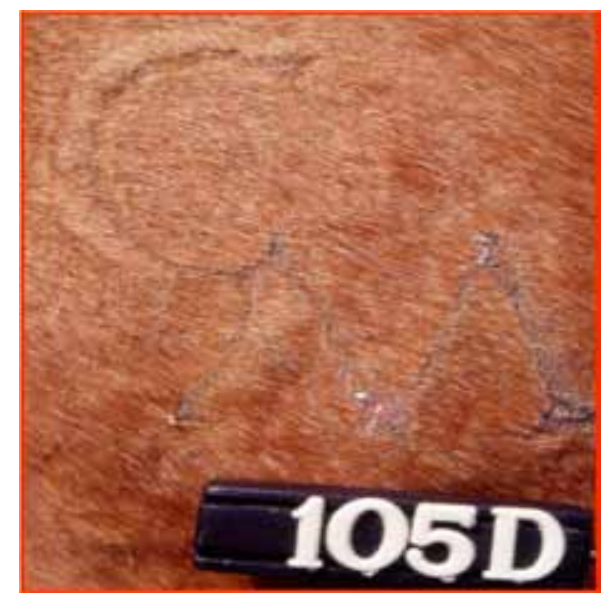

Figura 3. Marca a fuego completamente cicatrizada en equino de pelaje bayo ruano (día 105). 
del mismo color de la piel y bien visible. Es importante destacar que en algunos animales pueden aparecer cicatrices distintas de las esperadas como las exuberantes o queloides, las hiperpigmentadas o aquéllas con mayor grado de retracción y muy delgadas, que hacen difícil la visualización e interpretación del diseño de la marca.

Las heridas por quemadura pueden ser estériles o ser colonizadas por bacterias superficiales durante las primeras $24 \mathrm{~h}$. La presencia de tejido muerto constituye un medio excelente para la proliferación bacteriana; además, la oclusión del riego sanguíneo local imposibilita la llegada de mecanismos defensivos humorales y celulares. Solo persiste la irrigación en el tejido de granulación que está por debajo de la escara ${ }^{1,5,11}$. Por lo tanto podría manifestarse una infección bacteriana a los 4 o 5 días posteriores a este tipo de lesión ${ }^{1}$. En el presente caso y de acuerdo a lo que ocurre generalmente en las quemaduras producidas por la marca a fuego, la infección bacteriana no se presentó, posiblemente por la época del año en que se realizó la marcación (invierno).

Es importante mencionar que la temperatura de la fuente de calor y el tiempo en que ésta actúa sobre la piel son determinantes de la intensidad y profundidad de la quemadura que se puede producir ${ }^{1,5,6}$. En el hombre, las temperaturas superiores a $45^{\circ} \mathrm{C}$ pueden producir necrosis por coagulación y daño cutáneo irreversible; una temperatura de $49^{\circ} \mathrm{C}$ durante sólo 1 segundo produce una quemadura de espesor completo ${ }^{5}$. En la presente experiencia se han tenido en cuenta estos factores durante la maniobra de marcación, comprobando que para producir la quemadura de tercer grado, el hierro debió ser calentado al rojo y apoyado con firmeza, sobre la zona anatómica elegida, durante un tiempo de 2 a 3 segundos, siendo necesaria además una buena inmovilización del animal. De lo contrario, si el hierro no hubiera alcanzado la temperatura adecuada o el tiempo de apoyo no hubiera sido suficiente, sólo se hubieran provocado quemaduras de primer grado, que afectan solamente a la epidermis o de segundo grado, que destruyen la epidermis y parcialmente a la dermis, las que no dejan cicatriz ${ }^{1,5,6,11,12}$.

Se concluye que los cambios macroscópicos observados en este trabajo durante el proceso de cicatrización de una quemadura por marca a fuego son similares a los que se describen para las quemaduras en la bibliografía consultada y también son coincidentes en el tiempo que demanda la cicatrización total de una quemadura de tercer grado. Se espera que la descripción brindada constituya un patrón orientativo para determinar el tiempo aproximado en que fue estampada una marca a fuego en procesos periciales de abigeato y que le permita al médico veterinario fundamentar su informe pericial.

\section{REFERENCIAS}

1. Bojrab MJ. 1996. Fisiopatología y clínica quirúrgica en animales pequeños, $2^{\circ}$ ed., Intermédica, p. 157-159; 178184.

2. Carrazzoni JA. 1993. Historias de ganaderos y de veterinarios, Ed. Altuna, Buenos Aires, p. 27.

3. Código Procesal Civil y Comercial de la Nación. Art. 457. On line: http://www.in foleg.gov.ar/infolegInternet/ anexos/15000-19999/16547/texact.htm.

4. Código Procesal Penal de la Nación. Art. 253. On line: http://www.infoleg.gov.ar/infolegInternet/anexos/0-4999/ 383/texact.htm.

5. Fossum W. 2009. Cirugía en pequeños animales, $3^{\circ}$ ed., Elsevier, Madrid, p. 159-163; 228-232.

6. Garcia Alfonso C. 1982. Patología quirúrgica de los animales domésticos, $8^{\circ}$ ed., Científico-Médica, Barcelona, p. 33-48; 69-74.

7. Lightowler C, Mercado M. 1987. Contusiones y heridas, Hemisferio Sur, Buenos Aires, p. 88-92.

8. Régimen de marcas y señales de la Provincia del Chaco. Ley No 2972 y su modificatoria $\mathrm{N}^{\circ} 3018$. On line: http:// legislatura.chaco.gov.ar/InformacionLegislativa/datos/textos/word/00000160.DOC.

9. Slatter DB. 2006. Tratado de cirugía en pequeños animales, $3^{\circ}$ ed., Intermédica, Buenos Aires, p. 79-86.

10. Stashak T. 1994. Manejo de las heridas en equinos, Intermédica, Buenos Aires, p.1-12; 134-137.

11. Swaim SF, Henderson RA. 1992. Manejo de las heridas en los animales pequeños, Intermédica, Buenos Aires, p.17; 49-53.

12. Schwartz SS. 1995. Principios de cirugía, vol. I, $6^{\circ}$ ed., Interamericana, México, p. 236-238; 287-299. 